Thorax, 1978, 33, 211-213

\title{
Bronchial responsiveness to inhaled histamine and isoprenaline in patients with airway obstruction
}

\author{
M. K. BENSON \\ From Southampton University Hospitals, Southampton, Hants
}

\begin{abstract}
Benson, M. K. (1978). Thorax, 33, 211-213. Bronchial responsiveness to inhaled histamine and isoprenaline in patients with airway obstruction. In order to examine the hypothesis that bronchial reactivity to non-specific constrictor stimuli is influenced by the resting tone of the bronchial smooth muscle, the airway responses to inhaled histamine solution and inhaled isoprenaline were measured in 19 patients with airway obstruction. There was a significant positive correlation between the size of the constrictor response to histamine and the dilator response to isoprenaline $(\mathrm{r}=+0.83 ; \mathrm{P}<0.01)$ as measured by changes in specific airway conductance. Patients with asthma showed greater bronchial reactivity to both histamine and isoprenaline than those with chronic bronchitis, although some patients had changes intermediate between the two extremes.
\end{abstract}

Many studies have demonstrated the increased responsiveness of the bronchial tree to non-specific constrictor stimuli in patients with asthma and chronic bronchitis (Laitinen, 1974; Orehek and Gayrard, 1976). However, several hypotheses exist as to the underlying mechanism (Benson, 1975), and there is doubt as to the diagnostic usefulness of such tests in distinguishing asthma from bronchitis (Klein and Salvaggio, 1966).

Until recently little attention had been paid to the influence that the resting state of the airways may have in determining bronchial responsiveness. The baseline calibre of the bronchi is important since the relationship to the physiological tests used in assessing function is complex (Pride, 1971; Benson, 1975) and comparisons between individuals with different degrees of airway obstruction are difficult to interpret (Wells et al., 1960). A second factor concerns the resting degree of bronchospasm or bronchomotor tone. In studies of isolated muscle, combinations of smooth muscle agonists may be supra-additive (Sjöstrand, 1973; Finch et al., 1974). Thus, in patients with bronchospasm, the presence of endogenous mediators may potentiate the effect of an exogenous constrictor stimulus. In order to test this hypothesis, the airway responses to inhaled histamine and inhaled isoprenaline were compared in a group of patients with similar degrees of airway obstruction.

\section{Methods}

Patients were selected on the basis of having air- way obstruction of moderate severity as judged by measurements of airway resistance (Raw) and specific airway conductance (SGaw). Nineteen patients were studied, their ages ranging from 20 64 and baseline SGaw $0.8-1.2 \mathrm{~s}^{-1} \mathrm{kPa}^{-1}(0.08$ $\left.0.12 \mathrm{~s}^{-1} \mathrm{cmH}_{2} \mathrm{O}^{-1}\right)$. Clinical classification into one of three groups was made independently of the challenge results and was based on clinical and physiological observations made over at least one year before the study. Seven patients had chronic bronchitis, as judged by the Medical Research Council questionnaire, and had no subjective or objective variation in the degree of airway obstruction. Seven patients with asthma had documented episodic airway obstruction. In the remaining five patients there was diagnostic doubt. Although they had chronic cough and sputum production, they also complained of variable dyspnoea or wheezing. This group has been labelled as having 'asthmatic bronchitis'.

The patients were fully informed as to the nature of the study and gave their written consent. They were asked to avoid using any bronchodilator drugs for at least 12 hours before the study but to continue with any other therapy. Baseline measurements of airway resistance and thoracic gas volume were obtained during a 30-minute control period using a constant volume whole body plethysmograph. Patients were told that subsequent aerosols may make breathing better or worse or produce no change. Firstly, a freshly prepared $0.05 \%$ solution of histamine acid phosphate was given for one minute from a Wright nebuliser 
at a flow rate of $8 \mathrm{1} / \mathrm{min}$. At least five measurements of airway resistance and thoracic gas volume were made between one and two minutes later. Provided there was not a marked constrictor response, after 15 minutes' rest a second challenge of a $0.1 \%$ solution was given for two minutes, and the response was again measured 1-2 minutes later. The patients then rested for a further 30 minutes to allow airway resistance to return to control values before inhaling two puffs from a Medihaler Iso Forte (isoprenaline sulphate $0.8 \mathrm{mg}$ ). Airway resistance and thoracic gas volume were again measured five minutes later.

\section{Results}

Measurements of airway resistance, thoracic gas volume, and specific airway conductance together with the subsequent changes for each of the three groups are shown in the Table. Five patients with asthma had a large response to $0.05 \%$ histamine, and a second challenge was not given. The remaining patients all showed a significant response to $0.1 \%$ histamine. Since there were large changes in both airway resistance and thoracic gas volume the results shown in the Figure are the changes in specific airway conductance. Individual results show a significant positive correlation between the size of the constrictor response to histamine and the dilator response to isoprenaline $(r=+0.83$; $\mathbf{P}<0.01)$.

Comparison between the patients with asthma and those with chronic bronchitis shows the asthmatics to have greater changes in airway resist-

Table Airway responses to histamine and isoprenaline

\begin{tabular}{|c|c|c|c|}
\hline & Bronchitics & Asthmatics & $\begin{array}{l}\text { 'Asthmatic } \\
\text { bronchitics' }\end{array}$ \\
\hline $\begin{array}{l}\text { Control } \\
\text { Raw }\left(\mathrm{kPa} \mathrm{1}^{-1} \mathrm{~s}^{-1}\right) \\
\operatorname{TGV}(1) \\
\operatorname{SGaw}\left(\mathrm{s}^{-1} \mathrm{kPa}^{-1}\right)\end{array}$ & $\begin{array}{l}0.23 \pm 0.02 \\
4.3 \pm 0.7 \\
1.03 \pm 0.15\end{array}$ & $\begin{array}{l}0.22 \pm 0.03 \\
4.5 \pm 0.6 \\
1.05 \pm 0.07\end{array}$ & $\begin{array}{l}0.21 \pm 0.02 \\
4.8 \pm 0.9 \\
0.98 \pm 0.15\end{array}$ \\
\hline $\begin{array}{l}0.05 \% \text { Histamine } \\
\text { Raw } \\
\text { TGV } \\
\text { SGaw }\end{array}$ & $\begin{array}{l}0.27 \pm 0.02 \\
4 \cdot 4 \pm 1 \cdot 1 \\
0.93 \pm 0 \cdot 15\end{array}$ & $\begin{array}{l}0.46 \pm 0.11 \\
6.0 \pm 0.8 \\
0.39 \pm 0.12\end{array}$ & $\begin{array}{l}0 \cdot 27 \pm 0 \cdot 03 \\
5 \cdot 3 \pm 1 \cdot 0 \\
0 \cdot 71 \pm 0 \cdot 19\end{array}$ \\
\hline $\begin{array}{l}0.1 \% \text { Histamine } \\
\text { Raw } \\
\text { TGV } \\
\text { SGaw }\end{array}$ & $\begin{array}{l}0.36 \pm 0.08 \\
4.9 \pm 1 \cdot 2 \\
0.62 \pm 0.21\end{array}$ & $\begin{array}{l}0.61 \pm 0.07^{*} \\
7.4 \pm 0.1 \\
0.23 \pm 0.02\end{array}$ & $\begin{array}{l}0.39 \pm 0.12 \\
6.0 \pm 1.4 \\
0.48 \pm 0.2\end{array}$ \\
\hline $\begin{array}{l}\text { Isoprenaline } \\
\text { Raw } \\
\text { TGV } \\
\text { SGaw }\end{array}$ & $\begin{array}{l}0.17 \pm 0.02 \\
4.2 \pm 0.6 \\
1.43 \pm 0.25\end{array}$ & $\begin{array}{l}0.11 \pm 0.02 \\
4.0 \pm 0.5 \\
2 \cdot 46 \pm 0.39\end{array}$ & $\begin{array}{l}0.13 \pm 0.03 \\
4.8 \pm 1 \cdot 1 \\
1.64 \pm 0.3\end{array}$ \\
\hline
\end{tabular}

$* N=2$. Remainder of patients in this group received only $0.05 \%$ histamine.

Results given are mean $\pm 1 \mathrm{SD}$

Conversion SI to traditional units-

Raw: $1 \mathrm{kPa}^{-1} \mathrm{~s}^{-1}=10 \mathrm{~cm} \mathrm{H}_{2} \mathrm{O}^{-1} \mathrm{~s}^{-1}$.

SGaw $1 \mathrm{~s}^{-1} \mathrm{kPa}^{-1}=0.1 \mathrm{~s}^{-1} \mathrm{~cm} \mathrm{H}_{2} \mathrm{O}^{-1}$.

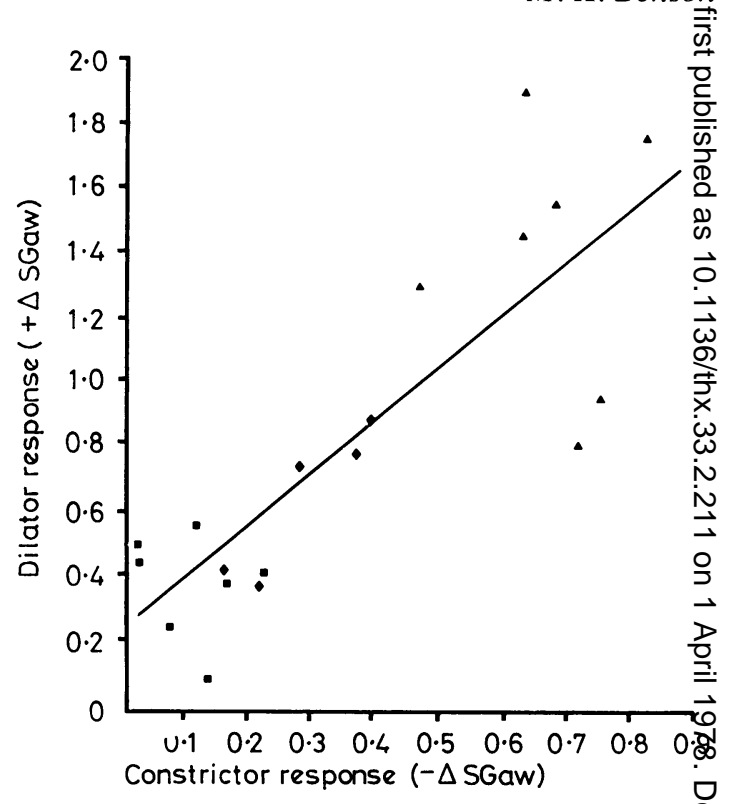

Figure Relationship between bronchodilator respon to isoprenaline and bronchoconstrictor response to $0.05 \%$ histamine acid phosphate, as measured by changes in specific airway conductance $\left(s^{-1} k P^{-1}\right)$ : $\Delta$ patients with asthma; patients with chronic bronchitis; $\downarrow$ patients with 'asthmatic bronchitis'.

ance and specific airway conductance to bot $0.05 \%$ histamine $(\mathrm{P}<0.001$, unpaired $t$ test $)$ and isoprenaline $(\mathrm{P}<0.001$, unpaired $t$ test $)$. Of the fie patients with asthmatic bronchitis, two hag changes similar to the bronchitic group while three had changes intermediate between the two extremes.

\section{Discussion}

In the patients studied there was a significa positive correlation between the bronchial re sponses to inhaled histamine and isoprenaline? Patients with bronchospasm, as shown by the large improvement after a bronchodilator, had a greatef constrictor response to histamine. Several factoge may contribute to this difference in responsiveness Firstly, the distribution of the aerosol may vary, may its bioavailability due to factors such \& mucus and mucosal oedema. Secondly, although an attempt was made to study patients with simila lung function, differences in the distribution of airway resistance may exist between patients. If addition, since there were changes in both lung volume and airway resistance after bronchia challenge, changes in lung compliance may be $\varrho$ factor in determining bronchial reactivity. Neve 
theless, the results are consistent with the hypothesis that the response to a bronchial muscle agonist is influenced by the resting bronchomotor tone. The basis for this hypothesis arises in part from studies in isolated muscle. Using a hypogastric nerve, vas deferens preparation, Sjöstrand (1973) has shown that low concentrations of muscle agonists enhance the motor response to nerve stimulation by reducing the threshold for firing of action potentials. Using airway muscle, Finch et al. (1974) have shown interaction between histamine and cholinergic stimuli. In vivo, electrical stimulation of the vagus nerves potentiates the effect of inhaled histamine and results in a shift of the dose response curve (Benson and Graf, 1977). Thus, in patients with asthma, the presence of endogenous spasmogens or increased vagal activity may serve to potentiate the effect of an exogenous stimulus.

Although the American Thoracic Society (1962) includes bronchial hyperreactivity in its definition of asthma, there is some doubt as to the usefulness of bronchial challenge tests in diagnosing asthma from bronchitis. Muittari (1968) established a significantly greater response to mecholyl in patients with asthma whereas Klein and Salvaggio (1966) showed that there was no useful diagnostic distinction between the two groups. In this study there were significant differences. There are several possible reasons for failure of agreement between the various studies.

(1) Clinical classification of a patient needs certain criteria for asthma and bronchitis other than bronchial responsiveness. While it is easy to separate young extrinsic asthmatics from older chronic bronchitics, there remains a group of usually middle-aged patients in whom the diagnostic criteria are imprecise.

(2) This study has attached considerable importance to comparing bronchial reactivity in patients with similar baseline lung function. Because of the exponential relationship between the radius of a tube and its resistance to flow, patients with pre-existing airway narrowing will have a greater increase in airway resistance for a given reduction of airway calibre.

(3) Any diagnostic test aimed at differentiating between two populations depends on there being a distinct bimodal distribution of results. Although the numbers of patients in this study are relatively small, they exhibit a spectrum of results.

As a diagnostic test in patients with asthma or bronchitis, the response of the bronchial tree to a constrictor stimulus is of no greater value than the response to a bronchodilator drug. It is in patients with no significant obstruction at the time of study that the response to a constrictor stimulus may be of diagnostic value (Parker et al., 1965).

I thank Professor J. B. L. Howell and Drs Anne Tattersfield and G. Sterling for allowing me to study patients under their care and for their helpful advice.

The work forms part of a thesis awarded for the degree of Doctor of Medicine at London University.

\section{References}

American Thoracic Society (1962). Chronic bronchitis, asthma and pulmonary emphysema. A statement by the committee on diagnostic standards for nontuberculous respiratory disease. American Review of Respiratory Disease, 85, 762-768.

Benson, M. K. (1975). Bronchial hyperactivity. British Journal of Diseases of the Chest, 69, 227-239.

Benson, M. K., and Graf, P. (1977). Bronchial reactivity: interaction between vagal stimulation and inhaled histamine. Journal of Applied Physiology, 43, 643-647.

Finch, P. J. P., Douglas, J. S., and Bouhuys, A. (1974). Interaction of humoral and vagal stimuli on airway smooth muscle of the guinea pig trachea in vitro. Physiologist, 17, 222.

Klein, R. C., and Salvaggio, J. E. (1966). Nonspecificity of the bronchoconstricting effect of histamine and acetyl-beta-methylcholine in patients with obstructive airway disease. Journal of Allergy, 37, 158-168.

Laitinen, L. (1974). Histamine and metacholine challenge in the testing of bronchial reactivity. Scandinavian Journal of Respiratory Diseases, Supplement 86.

Muittari, A. (1968). The value of the methcholine test as a diagnostic method in bronchospastic disorders. Annales Medicinae Internae Fenniae, 57, 197-203.

Parker, C. D., Bilbo, R. E., and Reed, C. E. (1965). Methacholine aerosol as test for bronchial asthma. Archives of Internal Medicine, 115, 452-458.

Pride, N. B. (1971). Assessment of airflow obstruction. British Journal of Diseases of the Chest, 65, 135169.

Orehek, J., and Gayrard, P. (1976). Les testes de provocation bronchique non-specifique dans l'asthme. Bulletin Européen Physiopathologie Respiratoire, 12, 565-583.

Sjöstrand, N. O. (1973). Effects of acetylcholine and some other smooth muscle stimulants on the electrical and mechanical responses of the guinea pig vas deferens to nerve stimulation. Acta Physiologica Scandinavia, 89, 1-9.

Wells, R. E., Walker, J. E. C., and Hickler, R. B. (1960). Effects of cold air on respiratory airflow resistance in patients with respiratory tract disease. New England Journal of Medicine, 263, 268-273.

Requests for reprints to: Dr. M. K. Benson, Saint Mary's Hospital, Milton, Portsmouth PO3 6AD. 